\title{
A Cross-Sectional Investigation of the Difficulties Encounter Arabic Students in Using English Adjectives: Error Analysis
}

\author{
Abir R El Shaban ${ }^{1, *}$ \\ ${ }^{1}$ Department of Teaching and Learning, College of Education, Washington State University, Pullman, USA \\ *Correspondence: Department of Teaching and Learning, College of Education, Washington State University, \\ Pullman, WA 99164-3251, USA. Tel: 1-617-447-6933. E-mail: abir.elshaban@wsu.edu
}

Received: April 10, 2017

Accepted: June 5, 2017 Online Published: Sptember 17, 2017

doi:10.5430/wjel.v7n3p29

URL: https://doi.org/10.5430/wjel.v7n3p29

\begin{abstract}
The author investigated the difficulties encounter Arab second language English learners in using English adjectives across four levels of English proficiency. Sixty students, fifteen from each year, were randomly selected. The subjects were undergraduate students at the English Department, Benghazi University, Libya. Test that covered most of the semantic and structural characteristics of English adjectives was used as an instrument of collecting data in this research. All of the errors were analyzed in the frame of Error Analysis Theory to second language acquisition. A Chi-square test of independence revealed that there is no significant difference in the types of errors (interference and developmental) committed by the students of the four years. Qualitatively, a through analysis of the types of errors and their possible causes were highlighted to assist ESL/EFL teachers and to help them reduce future problems regarding teaching English adjectives to Arab speaking learners of English as a second language.
\end{abstract}

Keywords: English adjectives; EFL/ESL students; Arab $2^{\text {nd }}$ language English learners; English grammar; error analysis

\section{Introduction}

Adjectives constitute a major word class in English, they are members of an open set, which is characterized by Lyons (1968) as "one unrestricted, indeterminably large, membership" (p. 436). Furthermore, not all words that are traditionally regarded as adjectives possess all the adjective characteristics, since certain adjectives are more 'adjective-like' than others; these are the prototypical adjectives. They comprise the set, which has most, or all of the properties which adjectives exhibit. If speakers are asked to give examples of adjectives, they are likely to provide prototypical examples, which correspond to central adjectives in Quirk et al (1985), such as big, happy. Quirk et al refer to criteria, which traditionally characterize central adjectives:

(1) Their free occurrence in 'attributive; function

e.g. a happy child;

(2) Their free occurrence in 'predicative' function

e.g. the child is happy;

(3) Their potential to be pre-modified by the intensifier very,

e.g. very happy;

(4) Their potential to appear in comparative and superlative constructions,

e.g. a happier child, the happiest child.

In most of the studies and textbooks designed for teaching English as a second language, adjectives have generally received less attention than other open set classes. This properly due to a 'pecking order' in lexical matters, seen from the grammarians' point of view. First in the pecking order are verbs. These are central to clause structure and intimately related to the discussion of transitivity, case, tense, and aspectual type. In second place come nouns not only for their role in realizing the arguments associated with verbs, but also because speakers refer predominantly to 'things' in the 
real world. Thus, English adjectives are the focus of this study. Error analysis will be used to explain common types of errors Arab second language learners make in using English adjectives.

\section{Types of Errors}

The main goal of this study is to investigate the types of errors intermediate and advanced Libyan learners encounter in using English adjectives, using error analysis that provides an actual attested problems rather than hypothetical ones and reveals the most common errors committed by Arab learners. Errors are a sign that the learner has not yet mastered the code of the target language. According to Corder (1978) the learner's errors are indicative of the state of the learner's knowledge and the ways the target language is learned. In order to recognize whether the errors committed by the second language learners are developmental or interference errors, it is worth to give a general idea of the two types of errors.

\section{Transfer Errors}

These types of errors are caused by mother tongue interference, for instance, in Arabic, adjectives can be used in plural form while in English they cannot. So, it is not uncommon that the learner transfers knowledge from his native language and pluralize English adjectives as in the cities of the blinds instead of in the cities of the blind.

\section{Developmental Errors}

These types of errors occur within the target language based on limited exposure to it. There are many types of developmental errors, they are:

Overgeneralization. It is defined by Jakobovits (1969) as the "use of previously available strategies in new situations" (p.55). Within such a strategy, learners deviate from the basic structure depending on their knowledge of other structures in the foreign language. This could be attributed to certain types of teaching techniques that increase the frequency of overgeneralizing structures. For example: Samir looks happy; *Samir looks a happy.

Ignorance of rule restrictions. In ignorance of rule restrictions, the learners apply some rules to structures where they do not apply. This type of error is closely related to overgeneralization errors. The learner is making use of an already learned rule in a new situation. These errors may be accounted for in terms of analogy and rote learning of rules. For example, if it is possible to use the - est superlative form with adjectives that do not have more than two syllables, then why not say * this actor is the famousest one instead of this actor is the most famous one.

Incomplete application of rules. Incomplete application of rules refers to the occurrence of structures whose deviancy represent the degree of development of the rules required to produce acceptable utterances. This can become obvious during a session where the teacher asks the learner a series of questions. The learner may produce unacceptable utterances such as:

Teacher Student

Is she the most beautiful? Yes, is she most beautiful.

Hypothesizing false concepts. Such errors occur because of the learners' false comprehension of the distinctions in the target language. These errors are sometimes due to poor gradation of teaching items. For example: *The green car is more faster than the red one. Such an error may due to the belief that the periphrastic more is a marker of the comparative form and it can also be used with an adjective of one syllable.

Strevens (1968) "hypothesized that errors should not be viewed as problems to be overcome, but rather as normal and inevitable features indicating the strategies that learners use." In his view, errors can be taken as motivation not of failure, but of success and achievement in learning. Errors, in this study, which did not fit systematically into either the first or second language system, were ignored.

\section{The Present Study}

The present study sets out to investigate the following hypothesis for each of the 16 questions:

- $H_{0}=$ There is not a significance difference in the causing of errors between the four years.

- $H_{a}=$ There is a significance difference in the causing of errors between the four years. 


\section{Methodology}

\subsection{Participants and Research Context}

The sample of the study is sixty students $(N=60)$; fifteen students have been chosen randomly from each of four years of the English language department at Benghazi University, Libya. All the participants are from the $1^{\text {st }}, 2^{\text {nd }}, 3^{\text {rd }}$ and $4^{\text {th }}$ year university students, aged 19-22 years. All were recruited for the test and provided with detailed information about the study. Moreover, those four year students represent two language proficiency levels: Intermediate $\left(1^{\text {st }}\right.$ and $2^{\text {nd }}$ year students) and advanced ( $3^{\text {rd }}$ and $4^{\text {th }}$ year students).

\subsection{Data Collection}

In order to investigate the different types of errors made by Arab learners of English, a test that is based on the description of adjectives was designed to analyze the types of errors Arab learners make in using adjectives in English. This test consisted of eighty-six items divided into sixteen questions. It covered most of the semantic and structural characteristics of English adjectives. The test was conducted during the department regular classes and supervised by four professors over four consecutive days with a time limit of 90 minutes were given to each group to test. The purpose of this cross-sectional study is to explore if there is any significance difference in the types of errors Arab second language (L2) English learners make in using English adjectives across the four years students and their two levels of English language proficiency.

\section{Findings}

In order to investigate the research hypotheses, Data were analyzed both qualitatively and quantitatively. Corder (1978) claims that "we need a qualitative classification of errors, and quantitative statement of the relative frequency of each type or error... and finally we need some explanation of the cause of each type of errors so that we undertake appropriate remedial measures" (p. 64). Therefore, along with qualitative analysis of types of errors Arab learners make, a Chi-square test of independence and goodness of fit were used as well.

\subsection{The Sequential Order of English Adjectives}

A Chi-square of independence was calculated to examine the difference between the causing of errors and students different proficiency levels. A non-significance difference was found $\chi^{2}(6, N=60)=9.52, p<.05$.

Table 1. Expected Counts from Observed Counts

\begin{tabular}{lrrr}
\hline Years & Interference & Developmental & Avoidance \\
\hline Year 1 & 1.024390244 & 5.12195122 & 0.8536585366 \\
Year 2 & 1.902439024 & 9.512195122 & 1.585365854 \\
Year 3 & 1.609756098 & 8.048780488 & 1.341463415 \\
Year 4 & 1.463414634 & 7.317073171 & 1.219512195 \\
\hline
\end{tabular}

The qualitative analysis of the test items answers showed that most systematic problems faced by Arab learners in this area are related to the selection of the right adjectival order. Their failure to distinguish between factual and opinion adjectives regarding what have to come first and next could be the reason for this difficulty. In addition to the fact that Arabic does not have rule for adjectival word order, since they have to be written according to the importance of meaning to the speaker. These are inherently difficult and would cause developmental errors. Further, other errors are attributed to inter-lingual where the noun precedes the adjectives viz. English in which adjective precedes the noun. Arab learner tend to say *house big vs. big house. Likewise, using adjectives as post modifiers as in: *Ball round red soft beautiful is another common error. Within the adjectival order, the interference errors are minor in comparison to the developmental ones.

\subsection{Adjectives that Express Opinion}

A Chi-square goodness of fit test was calculated comparing the numbers of avoided answers among the four years to determine whether observed sample frequencies differ significantly from expected frequencies specified in the null hypothesis. A non significant difference was found $\chi^{2}(3, N=60)=0.29, p<.05$. 
Table 2. Adjectives That Express Opinion

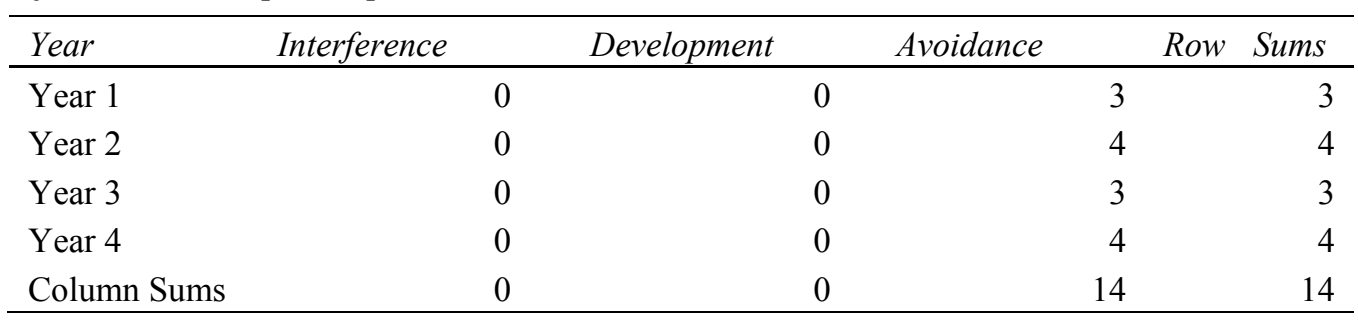

There is a considerable problem with the Arab students' ability to differentiate between 'opinion' and 'factual' adjectives. This lack of distinction between the two might be attributed to the fact that Arabic has no such difference and teachers of English may not concentrate on teaching this difference as it can be realized through the meaning from the context.

\subsection{The Participle Adjectives}

A Chi-square goodness of fit test was calculated comparing the numbers of developmental errors among the four years to determine whether observed sample frequencies differ significantly from expected frequencies specified in the null hypothesis. A non significant difference was found $\chi^{2}(3, N=60)=1.11, p<.05$.

Table 3. The participle adjectives

\begin{tabular}{lrrrr}
\hline Year & Interference & Development & Avoidance & Row Sums \\
\hline Year 1 & 0 & 3 & 0 & 3 \\
Year 2 & 0 & 4 & 0 & 4 \\
Year 3 & 0 & 6 & 0 & 6 \\
Year 4 & 0 & 5 & 0 & 5 \\
Column Sums & 0 & 18 & 0 & 18 \\
\hline
\end{tabular}

Most of the learners have a problem in either using the -ing or -ed in the subject-adjective agreement. Such errors are overgeneralizations. A logical reason might be, that Arab learners think that both meanings of adjectives either end in -ing or -ed are equivalents to be used with any subject. In addition, they might ignore that somebody is - ed if something (or somebody else) is - ing, i.e., Somebody is bored, if something (or somebody else) is boring; *The football match was quite excited.

\subsection{The Function of English Adjectives}

A Chi-square of independence was calculated comparing the causing of errors among the four years. A non significant difference was found $\chi^{2}(6, N=60)=8.69, p<.05$.

Table 4. The Function of English Adjectives

\begin{tabular}{lrrrr}
\hline Year & Interference & Development & Avoidance & Row Sums \\
\hline Year 1 & 6 & 2 & 1 & 9 \\
Year 2 & 7 & 1 & 0 & 8 \\
Year 3 & 8 & 8 & 0 & 16 \\
Year 4 & 6 & 1 & 0 & 7 \\
Column Sums & 27 & 12 & 1 & 40 \\
\hline
\end{tabular}

The most persistent problem faced by Arab learners in this area is related to the correct use of the attributive and predicative adjectives. English adjectives behave differently in English from Arabic. In terms of interference errors, learners tend to say, *the reason was main instead of the main reason was... Such structure is equivalent to the Arabic sentences in both meaning and form. Having said that, some learners ignore the use of the four principles of English adjectives as described by Quirk et al (1985). An example of the learners' developmental errors is their 
ignorance of the main functions of adjectives; some adjectives can be used only predicatively such as economic in *The economic crisis is in many countries.

\subsection{Adjectives Used Progressively and Imperatively}

A Chi-square test of independence was calculated comparing the causing of errors among the four years. A non significant difference was found $\chi^{2}(3, N=60)=1.74, p<.05$.

Table 5. Adjectives Used Progressively and Imperatively

\begin{tabular}{lrrrr}
\hline Year & Interference & Development & Avoidance & Row Sums \\
\hline Year 1 & 0 & 0 & 6 & 6 \\
Year 2 & 1 & 0 & 5 & 6 \\
Year 3 & 2 & 0 & 6 & 8 \\
Year 4 & 2 & 0 & 7 & 9 \\
Column Sums & 5 & 0 & 24 & 29 \\
\hline
\end{tabular}

Errors committed by learners, concerning adjectives that can be used progressively and imperatively cannot be attributed to first language interference, they are due to developmental errors only. The items of this question are closely related to the one concerning opinion adjectives, so students must know that only opinion adjectives can be used in both imperative and progressive form. Since, instead of choosing only the right opinion adjectives as friendly, brave ... etc, they also chose wrong objective ones as large, tall ... etc. learners commit such errors because of incomplete learning and inadequate attention given to teaching English adjectives. Table 5 shows that most of the learners adopted avoidance as learning strategy due probably to uncertainty or to unfamiliarity with the target language knowledge.

\subsection{The Suffixation of the Adjectives}

A Chi-square test of independence was calculated comparing the causing of errors among the four years. A non significant difference was found $\left(\chi^{2}(3)=0.76, p<.05\right)$.

Table 6. The Suffixation of the Adjectives

\begin{tabular}{lrrrr}
\hline Year & Interference & Development & Avoidance & Row Sums \\
\hline Year 1 & 0 & 7 & 6 & 13 \\
Year 2 & 0 & 6 & 5 & 11 \\
Year 3 & 0 & 8 & 5 & 13 \\
Year 4 & 0 & 7 & 3 & 10 \\
Column Sums & 0 & 28 & 19 & 47 \\
\hline
\end{tabular}

The majority of learners encountered difficulty in word formation. Students tend to make overgeneralization errors. They would say * inkind instead of unkind or *doubty instead of doubtful. So second language learners learn English have to be familiar with such combinations as they go. There are less than a hundred prefixes and suffixes in English. Some of them combine with, and/or form specific parts of speech, where as others combine with various bases or words, and/or form various parts of speech. Thus the prefix un- can combine with adjectives such as happy, kind, common ...etc, but it can also be added to verbs like do, dress, fasten ... etc. (Kharma \& Hajjaj, 1989).

Affixes are of a great help to vocabulary development. Learning different prefixes that mean negation is a very productive process for word building, and of a great help for comprehending the meaning of words. In addition, they help the learners to learn new words from words that might be already known. Although word-formation plays an important role in Arabic more than in English, errors committed by Arab learners cannot be attributed to interference, all are developmental as in:*senseful, *advising, *woolly, *doubtable.

\subsection{The Pre-Fixation of the Adjectives}

A Chi-square test of independence was calculated comparing the causing of errors among the four years. A non significant difference was found $\chi^{2}(3, N=60)=1.84, p<.05$. 
Table 7. The Pre-Fixation of the Adjectives

\begin{tabular}{lrrrr}
\hline Year & Interference & Development & Avoidance & Row Sums \\
\hline Year 1 & 0 & 8 & 6 & 14 \\
Year 2 & 0 & 4 & 2 & 6 \\
Year 3 & 0 & 5 & 6 & 11 \\
Year 4 & 0 & 6 & 2 & 8 \\
Column Sums & 0 & 23 & 16 & 39 \\
\hline
\end{tabular}

Students' responses indicated a developmental errors, they tend to say *unlegal instead of illegal, *unresponsible instead of irresponsible, *inkind instead of unkind. In this section the first year subjects have more difficulty than the others, following them the third year subjects and the fourth year subjects. The second year subjects have the least difficulty in this section.

\subsection{Plurality of the Adjectives}

A Chi-square test of independence was calculated comparing the causing of errors among the four years. A non significant difference was found $(3, N=60)=0.94, p<.05$. All of the four years students are most likely to make interference errors (3).

Table 8. Plurality of the Adjectives

\begin{tabular}{lrrrr}
\hline Year & Interference & Development & Avoidance & Row Sums \\
\hline Year 1 & 3 & 0 & 1 & 4 \\
Year 2 & 3 & 0 & 1 & 4 \\
Year 3 & 3 & 0 & 1 & 4 \\
Year 4 & 3 & 0 & 0 & 3 \\
Column Sums & 12 & 0 & 3 & 15 \\
\hline
\end{tabular}

Probably one of the sources of difficulty that encounter Arab learners in plurality might be due to interference. In Arabic adjectives can be used in the plural form, whereas in English, adjectives cannot have the plural form. They can only have the implied plural meaning. Another reason for committing such errors by Arab learners which due to interference; is considering adjectives as nouns. Students add the noun plural ending to the adjective, e.g., *In the countries of the blinds the one-eyed men are kings, and *When the riches make wars, they are the poors who die. This is because they ignore that occasionally the adjective is used as a noun and takes the definite article and cannot be pluralized.

\subsection{The Comparative and Superlative Form of the Adjectives}

A Chi-square test of independence was calculated comparing the causing of errors among the four years. A non significant difference was found $\chi^{2}(3, N=60)=1.78, p<.05$. All of the four years students are most likely to make developmental errors (7), none of them committed interference errors within the comparative and superlative form of the adjectives.

Table 9. The Comparative and Superlative Form of the Adjectives

\begin{tabular}{lrrrr}
\hline Year & Interference & Development & Avoidance & Row Sums \\
\hline Year 1 & 0 & 7 & 1 & 8 \\
Year 2 & 0 & 7 & 1 & 8 \\
Year 3 & 0 & 7 & 2 & 9 \\
Year 4 & 0 & 7 & 0 & 7 \\
Column Sums & 0 & 28 & 4 & 32 \\
\hline
\end{tabular}

Arab learners have lack of knowledge that only short adjectives need -er, in comparative and -est for the superlative form. In addition, most of the developmental errors made in this area are done through mistakenly adding the wrong 
suffix to the root adjective. For instance, instead of saying, it's the longest day of the year, they say, *It's the longer day of the year.

Moreover, they missed the use of the periphrastic more- in the comparative and the most - in the superlative with adjectives of more than two syllables. Instead they used the markers -er and -est as in *sensitiver than instead of more sensitive than. In addition to their incorrect use of the irregular adjectives form, for instance they would write *bader instead of worse and *farest instead of furthest.

\subsection{The Qualification of the Adjectives}

A Chi-square test of independence was calculated comparing the causing of errors among the four years. A non significant difference was found $\chi^{2}(6, N=60)=1.65, p<.05 .3^{\text {rd }}$ and $4^{\text {th }}$ year students are most likely to commit interference errors (4) than the other two years. Also, $3^{\text {rd }}$ year students tend to commit more developmental errors (4) within the qualification of the adjectives.

Table 10. The Qualification of the Adjectives

\begin{tabular}{lrrrr}
\hline Year & Interference & Development & Avoidance & Row Sums \\
\hline Year 1 & 3 & 2 & 4 & 9 \\
Year 2 & 3 & 3 & 5 & 11 \\
Year 3 & 4 & 4 & 4 & 12 \\
Year 4 & 4 & 3 & 2 & 9 \\
Column Sums & 14 & 12 & 15 & 41 \\
\hline
\end{tabular}

The main problem Arab students face in qualification the adjectives is their tendency to add the qualifier after the adjective. In other words, their main problem with the use of qualifiers is related to word order. Such mistakes are due to interference from the first language as in: *The house was enough comfortable; *He is a happy very child. In English, the position of the qualifier is usually before the adjective. Only enough can be used after the adjectives. Other error committed by Arab students in this area is concerning the misunderstanding of the right meaning of the qualifier to be equivalent to the adjective. Such errors cannot be related to interference.

\subsection{Clauses of the Adjectives}

A Chi-square test of independence was calculated comparing the causing of errors among the four years. A non significant difference was found $\chi^{2}(3, N=60)=0.49, p<.05$. 1st year students are most likely to commit interference errors (8) within the clauses of the adjectives.

Table 11. Clauses of the Adjectives

\begin{tabular}{lrrrr}
\hline Year & Interference & Development & Avoidance & Row Sums \\
\hline Year 1 & 0 & 8 & 6 & 14 \\
Year 2 & 0 & 7 & 4 & 11 \\
Year 3 & 0 & 6 & 6 & 12 \\
Year 4 & 0 & 5 & 4 & 9 \\
Column Sums & 0 & 26 & 20 & 46 \\
\hline
\end{tabular}

Students do have special problems with certain prepositions, which collocate differently with adjectives. Learners have problems in using - ing clause, that clause, wh-clause, to infinitive clause and than clause. For example, they committed errors in:

- The use of-ing clause, e.g., * James is busy to preparing tonight's dinner

- The use of to infinitive clause, e.g., *It's hard of him to accepting that he was wrong

- The use of that clause, e.g., *We were amazed in your managed to fin us 
- $\quad$ The use of preposition and -ing clause, e.g., *She is interested by buying a new car

4.12 Whether the Sentences Are Right or Wrong

A Chi-square test of independence was calculated comparing the causing of errors among the four years. A non significant difference was found $\chi^{2}(3, N=60)=0.82, p<.05 .1^{\text {st }}$ and 4 th year students are most likely to commit developmental errors (10) than the other years within whether the sentences are right or wrong.

Table 12. Whether the Sentences Are Right or Wrong

\begin{tabular}{lrrrr}
\hline Year & Interference & Development & Avoidance & Row Sums \\
\hline Year 1 & 0 & 10 & 1 & 11 \\
Year 2 & 0 & 9 & 1 & 10 \\
Year 3 & 0 & 8 & 0 & 8 \\
Year 4 & 0 & 10 & 1 & 11 \\
Column Sums & 0 & 37 & 3 & 40 \\
\hline
\end{tabular}

More than $50 \%$ of each of the subjects of the four years failed to mark the right sentences only which are mixed with wrong ones. Most of them ignore that the adjective elder, for instance, does not imply comparative as in *I am elder than you. Also they ignore that certain adjectives such as perfect cannot be used in comparative form explicitly as in * expensive products are often more perfect. In addition to their ignorance that all the adjectives in any function can never be pluralized as in *we must not forget that some criminals are the riches people.

\subsection{The Semantic Function of the Adjectives}

A Chi-square test of independence was calculated comparing the causing of errors among the four years. A non-significant difference was found $\chi^{2}(3, N=60)=2.56, p<.05$. The 3rd year students are most likely to commit developmental errors (6) than the other years and the $4^{\text {th }}$ year students are most likely to commit developmental errors than the other groups within the semantic function of the adjectives.

Table 13. The Semantic Function of the Adjectives

\begin{tabular}{lrrrr}
\hline Year & Interference & Development & Avoidance & Row Sums \\
\hline Year 1 & 0 & 5 & 3 & 8 \\
Year 2 & 0 & 5 & 4 & 19 \\
Year 3 & 0 & 6 & 4 & 10 \\
Year 4 & 0 & 5 & 5 & 10 \\
Column Sums & 0 & 31 & 16 & 47 \\
\hline
\end{tabular}

Most of the students failed to differentiate between modifier and sub-modifier, modifier and qualifier, the head adjective and noun. The learners' failure to assign the semantic function of adjectives proved that they have to be taught from a functional point of view. Henceforth, learners will encounter less difficulty in dealing with them. The type of errors related to this area of study is developmental. The students failed to distribute the adjectival group in the right function as in:

\begin{tabular}{|c|c|c|c|}
\hline Sub-modifier & modifier & head (adjective) & qualifier \\
\hline \multirow[t]{3}{*}{$* a$} & *hopeless & ${ }^{*}$ memory & *for names \\
\hline & ${ }^{*}$ too & * easily & *forgotten \\
\hline & & ${ }^{*}$ a braver & ${ }^{*}$ man than *him \\
\hline
\end{tabular}

\subsection{Translation}

A Chi-square test of independence was calculated comparing the causing of errors among the four years. A 
non-significant difference was found $\chi^{2}(6, N=60)=1.48, p<.05$. The 3 rd year students are most likely to commit interference errors (3) than the other years and the $3^{\text {rd }}$ and $4^{\text {th }}$ year students are most likely to commit developmental errors (6) than the other groups within translation.

Table 14. Translation

\begin{tabular}{lrrrr}
\hline Year & Interference & Development & Avoidance & Row Sums \\
\hline Year 1 & 2 & 4 & 2 & 8 \\
Year 2 & 2 & 4 & 2 & 8 \\
Year 3 & 3 & 6 & 1 & 10 \\
Year 4 & 2 & 6 & 1 & 9 \\
Column Sums & 9 & 20 & 6 & 35 \\
\hline
\end{tabular}

Most of the errors are because of the Arabic language interference, as an illustration, some learners omit the verb to $b e$. This is because of the absence in Arabic nominal sentences in the present tense of an equivalent of the English verb to be as in, *the girl beautiful/ al fatato gamilah. Also because of the first language interference, many students were confused to use either of, i.e., strange, foreign, freak (referring to a man, the second and the third are used instead of strange) as in, *I saw a freak man. Moreover, verb-subject instead of subject-verb order was also a common cause of error committed by the four years subjects as in, *looks Armed happy/ yabdu ahmed sa3i:d. For exclamations, many of the subjects used How instead of What as in, *How a beautiful day!

Again translation from Arabic into English proved that the majority of the subjects have a real difficulty both in adjectives word order as interference errors in which they write the head noun before the rest of adjectives. Also, they committed developmental error that is related to their incorrect use of the order of English adjectives as in, *I bought square red beautiful Iranian carpet. Table 14 shows that all of the four years subjects encounter difficulty in translation. The third year subjects have the highest percentages of errors both in interference and developmental, then the fourth year subjects. Generally, the counts of the developmental errors committed by the four years subjects were higher than the interference errors. The second year subjects have the highest percentage of avoided answers, then the fourth year subjects. Both of the first and the third year subjects have equal counts of avoided items.

\subsection{Synonymy and Antonym of the Adjectives}

A Chi-square test of independence was calculated comparing the causing of errors among the four years. A non-significant difference was found $\chi^{2}(3, N=60)=7.73, p<.05 .1^{\text {st }}$ year students are most likely to commit interference errors (4) than the other groups within synonymy of the adjectives.

Table 15. Synonymy and Antonym of the Adjectives

\begin{tabular}{lrrrr}
\hline Year & Interference & Development & Avoidance & Row Sums \\
\hline Year 1 & 0 & 4 & 1 & 5 \\
Year 2 & 0 & 2 & 0 & 2 \\
Year 3 & 0 & 3 & 0 & 3 \\
Year 4 & 0 & 0 & 2 & 2 \\
Column Sums & 0 & 9 & 3 & 12 \\
\hline
\end{tabular}

Many learners encountered difficulty with both synonymy and antonyms of adjectives. They are aspects of language learning, which have been largely neglected. Consequently Hajaji and Kharma (1989) stated the following:

This neglect is all the more striking in those learners themselves readily admit that they experience considerable difficulty with vocabulary, and once they have got over the initial stage of acquiring their second language, most learners identify the acquisition of vocabulary as their greatest single source of problems. Furthermore, in most methodology books, the teaching of vocabulary is either ignored altogether, or allotted an insignificant place (p.83).

Therefore, fair contrasting aspects of English and Arabic vocabularies would illuminate the difficulties of learners as 
with Freak, strange. Also the students should be trained to look for the proper use of words in various contexts. Table 15 shows that none of the four years subjects committed interference errors. All of the errors are attributed do developmental errors. The first year subjects have the highest percentage of developmental error, then the third year subjects and the second year subjects. The fourth year subjects don't have any errors, yet they have the highest percentage of avoided answers as a learning strategy adopted by them. Also, the first year subjects avoided answering some answers, non- of the second and the third year subjects have unanswered items. Errors in matching words that have nearly the same meaning (synonymy) are those like matching funny with wealthy instead of amusing and rich with brilliant instead of wealthy.

4.16 Antonym of the Adjectives

A Chi-square test of independence was calculated comparing the causing of errors among the four years. A non-significant difference was found $\chi^{2}(3, N=60)=7.55, p<.05$.

Table 16. Antonym of the Adjectives

\begin{tabular}{lrrrr}
\hline Year & Interference & Development & Avoidance & Row Sums \\
\hline Year 1 & 0 & 5 & 1 & 6 \\
Year 2 & 0 & 3 & 2 & 5 \\
Year 3 & 0 & 4 & 0 & 4 \\
Year 4 & 0 & 1 & 4 & 5 \\
Column Sums & 0 & 13 & 7 & 20 \\
\hline
\end{tabular}

Table 16 shows that none of the four years subjects committed interference errors. All of their errors are attributed to the developmental errors. The first year subjects have the highest percentage of the developmental errors, then the third year subjects, and the second year subjects. The fourth year subjects have the lowest counts of developmental errors, yet they have the highest counts of avoided answers, then the second year subjects and the first year subjects. The third year subjects have 0 counts of avoided answers.

Errors in matching words that have nearly opposite meaning are those like matching shallow with curved instead of deep and straight with dim instead of curved. It is worth to mentioning that most of the subjects did not have any difficulty in matching polite with impolite. However, the problem that could lead the subjects not to match words correctly might due to the fact that vocabulary acquisition as an aspect of language learning has been largely neglected, so subjects experience considerable difficulty with vocabulary. Moreover, in most methodology books, the teaching of vocabulary is either ignored at all or just given an insignificant consideration.

\section{Discussion}

The main aim of this study was to investigate the difficulties encountered by Arab students in using English adjectives. The analysis of the test items, which covered the most frequent meanings and structural functions of English adjectives, in terms of Chi-square test of independence showed that there is not a significance difference in the causing of errors among the four different groups.

The lack of significance in this test signals that there is not enough evidence to say there is a relationship between the error type and year in the program. However, it is noticeable from the tables that the higher the learner's level is, the greater is the difficulty. The qualitative analysis has confirmed Taylor's view (1975) that "as the learner learns more about the target language the number of his errors attributable to the target language syntactic overgeneralization will increase" (p. 87). Although these issues cannot be generalized, they give indications about the difficulties that the Arab learners encounter. What's worth to be notice is that developmental errors have played a major part in the learners' erroneous responses, where as interference errors have played only a minor part. The majority of the learners' errors are overgeneralization errors.

Further, from the analysis of the types of developmental errors, it seems that there is an overlap between these types of errors. If we look at the example, this actor is the famousest one, it could be assumed that this error is due to overgeneralization, ignorance of rule restrictions, incomplete application of rules or hypothesizing false concepts. The researcher has noticed from the interpretation of the data that the subjects' performances on the test items are 
approximately similar. Most of the learners' errors are developmental rather than interference, for instance $1^{\text {st }}$ year developmental errors are $\left(27.98 \%\right.$ to $5.50 \%$ respectively), the $2^{\text {nd }}$ year are $\left(26.35 \%\right.$ to $6.04 \%$ respectively), the $3^{\text {rd }}$ year are $\left(29.53 \%\right.$ to $7.28 \%$ respectively), and the $4^{\text {th }}$ year are $(26.89 \%$ to $6.35 \%$ respectively). These results revealed that the third year learners committed the highest percentages show more errors of both the target language and the native language. Therefore, a pedagogical consideration of English adjectives is of a real need.

\section{Conclusion}

On the basis of the findings of the research, we would recommend that EFL/ESL teachers consider the following points when teaching English adjectives.

- Error analysis is a good tool for identifying the areas of difficulties for the learner. Thus, from a pedagogical point of view, it can help (a) in determining the sequence of presentation of target items in textbooks and in the classroom, going from easy to more difficult; (b) in devising remedial lessons and exercises and (c) in selecting items for testing the learners' proficiency.

- Although "we all know that patterns learned first has priority over patterns learned at a later date" (Richard \& Sampson, 1974, p. 14), learners' interference errors were very minor in comparison with developmental errors and unanswered items.

- To illuminate the amount of learners' problems such as those with English adjectives, a new pedagogical approach is really needed.

- The Systemic Functional Approach is an appropriate model for teaching. Especially in describing the systems of meanings and their forms.

- Researching the other parts of lexicogrammatical items such as adverb, verb, and noun is recommended since this study focused on Adjectives only.

\section{References}

Corder, S. P. (1974). Error analysis. The Edinburgh course in applied linguistics, 3, 122-131.

Jakobovits, L. A. (1969). Research findings and foreign language requirements in colleges and universities. Foreign Language Annals, 2(4), 436. https://doi.org/10.1111/j.1944-9720.1969.tb00321.x

Kharma, N., \& Hajjaj, A. (1989). Errors in English among Arabic speakers: Analysis and remedy. Longman.

Lyons, J. (1968). Introduction to theoretical linguistics. Cambridge: Cambridge University Press. https://doi.org/10.1017/CBO9781139165570

Quirk, R., Greenbaum, S., Leech, G., \& Svartvik, J. (1985). A comprehensive grammar of the English language. London and New York: Longman.

Taylor, B. (1975). The use of overgeneralization and transfer learning strategies by elementary and intermediate students of ESL. Language Learning, 25, 73 -107. https://doi.org/10.1111/j.1467-1770.1975.tb00110.x 